Informal Logic

X.3, Fall 1988

\title{
The Unspeakable: Understanding the System of Fallacy in the Media
}

\author{
JOHN McMURTRY University of Guelph
}

\begin{abstract}
" The universal conspiracy of the silentassertion lie is hard at work always and everywhere, and always in the interest of a stupidity or a sham, never in the interest of a thing fine or respectable... The silent colossal National Lie that is the support and confederate of all the tyrannies and shams and inequalities and unfairnesses that afflict the peoples - that is the one to throw bricks and sermons at. But let us be judicious and let someone else begin."
\end{abstract}

Mark Twain
("My First Lie,", 1898)

At the heart of informal logic is its concern to detect fallacious structures of reasoning in natural language discourse. The normal procedure is: where we are able to identify a flaw in premise, inference, relevance or the like in any route of reasoning, we hold that a fallacy has been committed and we seek to demonstrate it. Otherwise put, logical analysis is directed at what is argued, and fallacies are found in this or that particular way of arriving at a conclusion.

This method of analysis is indispensable to sound logical construction of individual arguments, but misses the overall pattern of assertion and non-assertion for the particular claims within it. What has been so far overlooked is that reasoning can be misled not only in its steps of making a case, but by what is ruled out from being made a case: not only by what is wrong within this or that route of assertion, but by what is wrong with the structure of these routes of assertion taken together. We have, that is, missed the forest for the trees, or more accurately, for the logical landscape within which the forest and trees are located.
I will argue that there is a deeper, more comprehensive structure of subverting reason that misleads our thinking across propositional routes, and not through any fallacy of any such route. And I will show that this disorder obstructs and deforms our thinking and our reasoning by a general system of deception which has so far operated underneath the reach of our tools of logical detection and correction.

\section{The Parable of the Logical Dictator}

Consider an example. We shall call it the Parable of the Logical Dictator. Let us imagine the Logical Dictator as a sort of contemporary philosopher-king who presides over a global empire of thought. As such, he has monopoly control of the mass media of communication whereby claims or arguments or any other expressions or sequences of meaning can be made public in the society over which he presides. Being a devotee of logical soundness in all areas of communications exchange, he prescribes a rigorous obedience of his media managers to warranted premises, inferenceroutes and conclusions in all arguments or proto-arguments which occur in his society's public communications network.

The empire's leading logicians effectively serve the regime in an advisory capacity, and a system of public censures and punishments over time successfully deters the commission of any error of consistency or fact in media reports, claims, analyses, editorial comments and so on. Yet the Logical Dictator, being a cunning 
dictator, ensures, without anywhere allowing on pain of instant dismissal this pattern of proscription to be stated, that nothing which in any way contradicts the necessity or value of this rule shall be admitted into any media report or discussion.

Over time, he and his advisors so finetune this system of selection and exclusion of what can and cannot be said, that no event or issue is ever selected for public presentation whose domain of reference is such that it could permit the question of the necessity or value of the dictator's rule to be relevantly raised (as distinguished from those questions or issues relating to this rule's proper protection and execution).

In this way, the Logical Dictator successfully abolishes critical thinking at the deepest level of concern, prescribes untruth and unreason by negation without falling prey to a known fallacy, and succeeds in instituting a logically foolproof but systematically misleading discourse for the imperium of thought which he controls.

\section{The Problem}

The problem is thus posed: How are we to expose this system of unreason? There is no doubt that such a structure of distortion can obstruct and mislead the course of inquiry and understanding more deeply than any fallacy of argument to which we now direct our attention. Yet it is precisely because its flaw is in this way beyond the reach of detection within any argument that our current logical analysis is incapable of convicting its underlying system of deception. ${ }^{1}$

Given that the monopoly powers of our Logical Dictator are, as a matter of fact, more or less isometric with the actual design of mass communications control in our world, the problem that confronts us here is by no means unreal in its bearings. ${ }^{2} \mathrm{We}$ might even say the parallels of our fable and reality extend further. Our ascription to the Logical Dictator of a strict adherence to sound logical form is akin in principle to the adherence by the actual communications media to what is called "objectivity". In both cases, the transpropositional structure of unreason over which this rule extends remains perfectly consistent with "accuracy" or credible premises, "consistency" or valid inferences, and "impartiality" or suspension of personal viewpoint.

\section{The Underlying System of Fallacy}

Let us now identify the precise parameters of this covert structure of misleading reason. We begin with the principle which defines the underlying pattern of power in accordance with which it operates.

\section{Principle I:}

There is a basic social-structural fact (B.S.S.F.). Its defining principle, applicable to most or all existing social orders, is that large capitalist corporations or a state party control production and distribution of social goods so as to maximize private capital or social command owned by these capitalist corporations or state party.

This principle allows for much variation in the degree of control it refers to, in the nature of production and distribution systems involved, in the extent of ownership maximization these systems generate, and in the consequences for respective social populations. We cannot enter here into the vast complexity of such variations. But we need not. For all such variations in basic social-structural fact are subsumed by the general principle we have specified.

The Communist Party of the Soviet Union, for example, directs the production and distribution of social goods in the U.S.S.R. in a much different way than the Fortune 500 does in the United States. The one's traditional basis of power lies in monopoly control of state institutions, and the other's lies in the accumulation of 
private capital. But both systems conform to Principle I. On the other hand, the Prophet's mullahs in Iran or the militarybureaucratic elite of Indonesia hold and extend their more extreme systems of social command in different ways again-by bases of power that are imposed on production and distribution of goods from above by religious or military decrees. But at the level of logical analysis, at the highest level of generality, all these systems express an underlying, common principle as widely variant instances of it. These empirical variations we must leave to historians and social scientists. Their underlying principle, however, is of fundamental relevance to analysis of public discourse and communication, for it defines the regulative structure of context within which public discourse and communication are situated.

Our next step of analysis, then, is to formulate the relationship between this structure of context and what is said and otherwise publicly conveyed in the society whose communications we analyse. From a distance, we can make out the lines of this relationship more or less clearly. For example, we can see that the control of the production and distribution of social goods by the traditional Communist Party in the Soviet Union or the mullah theocracy of Iran relates to what is publicly said in that society in such a way that this public communication remains consistent with this control. Indeed this connection has come to be accepted as more or less lawlike as historical experience has disclosed countless cases of persecution or liquidation of voices in these societies which have opposed or contradicted their context of social rule. Our problem as logicians has been that we have not understood this relationship between context of power and public communication in principle, in terms of a generalizable rule of determination obtaining across discourse boundaries and differences. We have been inclined rather to remain confined within our own culture for the arguments and proto-arguments we diagnose, and to assume that because no such social control exists here to fence in and to deform public discourse, we may analyze for disorders or reasoning with no such basic contextual bearings. This near-sightedness has caused us, since Aristotle, to search only for those disorders of reasoning that occur within argument sequences, and not to consider the logical disorders that may occur from reasoning's subjection to what is outside of it, its context of social regime. We readily acknowledge the repression and distortion of thought and reason by such determination in alien cultures, but have not achieved the plane of abstraction that is required to treat this problem as a general one, and to excavate its deep structure of deception. We have in this way missed a fundamental system of unreason that misleads us underneath individual error and ruse at the intersubjective and cultural level.

To define the linkage principle between structure of social rule and public communication in such a way as to maintain a sufficiently high level of abstraction that all particular empirical variations are subsumed by it, is not a task to which either social scientists or logicians of natural language have bent themselves. The former have been confined to empirical description and analysis of geographically or temporally bound contexts; while the latter have restricted their analysis to what is asserted, independent of the social context within which assertions occur. Even where the relationship between public communication and its contextualizing relations of power has been studied in detail for its distortive effects, most notably by Noam Chomsky, its underlying general principles and rules have not been investigated in a systematic way. ${ }^{3}$ The relationship remains obscured by its particular cultural manifestations or, at the other extreme, is not considered at all. Nevertheless, the missing prime principle from which a general system of fallacy is generated can be formally defined as follows: 
Principle II:

Corresponding to the basic socialstructural fact as defined by Principle $I$, is a range of possibility of what can be said in the mass media of the society in question. This range of possibility is defined, in turn, as whatever does not contradict the necessity or value of this basic socialstructural fact.

The range of possibility of what can be said in the mass media, that is, extends only so far as its formulations are consistent with accepting the B.S.S.F. of the society concerned as necessary and preferable to others. Conversely, where such formulations are not consistent with acceptance of the B.S.S.F., they are ruled out.

It follows from Principle II, then, that any evidence, issue or argument that would expose the replaceable inefficiency, the moral fraudulence, the historical inadequacy or the civic underdevelopment of a society's major capital owners, state-party nomenklatura, theocractic rulers, or whatever, will be ruled or selected out of that society's media discourse. There will be degrees of exclusion here, from a priori unspeakable to marginalized exception. And there will be various methods of excommunication, from non-publication of the text itself to physical assassination of its author. ${ }^{4}$ Whatever the degree and method of exclusion, however, the range of what can be socially said, and thus asserted or reasoned, is limited by the conditions of the regime within which it arises in such a way as to rule out whatever does not conform to these conditions: however substantiated, reasonable, or logically plausible such proscribed positions might be.

This principle of exclusion that determines what can and cannot be asserted and reasoned in public-which thus identifies what prohibits all statements which do not conform to these a priori limits-is testable. As we shall soon illustrate, its operation is systematically confirmed by the evidence of mass media productions across the world.
The preclusion of reason the principle identifies includes, most importantly, this principle itself.

We have now the existential ground, a more or less universal social-structural fact admitting of variations within its unifying pattern. We have, as well, the existential consequent of this ground, a specifiable range of public discourse possibility, within which reasoning must remain confined to qualify as a candidate for public communication. We have, finally, the entailment of this consequent, that any step of reason which is not consistent with the principle defining this range will be ruled or selected out of public discourse. ${ }^{5}$

The ways in which Principle II is instantiated in different contexts of social power is, as with Principle I, an empirical issue. The mullahs of Iran may pronounce a sentence of death on the speaker of the unspeakable, in accordance with how deeply his thoughts have contradicted the necessity or value of their social rule (e.g., by representing the divine ground of their legitimacy as the contrivances of a fallible man). The members of the Politbureau of the U.S.S.R. may direct that a person be demoted or exiled for challenging the right of the Communist Party leadership to determine the future of the nation. The military bureaucratic elite of Indonesia may decree life-incarceration or death for persons who assert the state ideology of Pancasila is a pretext for the self-enriching power of this same military-bureaucratic elite. And so on. But because such practices of state interference with free speech do not normally occur in advanced Western societies, we may be misled into supposing that the principle of exclusion in question is therefore not generalizable across the boundaries of public communication and thought.

This conclusion does not follow. Principle II allows for very different modes of its realization. A succession of "gates" or "filters" in the many-staged process of mass-media production in the Western world can limit in a more sophisticated way 
the range of what is publicly said without any such state intervention involved: through the hiring, transfer or firing of those who edit, those who report and those who state arguments at all levels of the communications enterprise; through the selection of which issues and events to cover and which not to cover; through the assignment of time and staff to produce representations of what is selected for report; through the choice of what articles, sentences and words are to be published from the copy that comes in; through the prominence, placement, headlines and pictures that accompany what is produced; and through-most importantly - what is reproduced over time in this many-phased process of selection and exclusion.

This system of mediations merely extends the operation defined by Principle II through a succession of constituent steps, rather than concentrating it in a single intervention by the state. In this way, it may be a more effective because less visible system of thought control. Because, however, our acculturation by the very mass media this system mediates may make us peculiarly unwilling to accept their conformity to Principle II in the face of our sense of variety of viewpoint, pluralist politics, consumer sovereignty, freedom to read and watch what we wish, and so forth, we need to appeal to some rational test of this principle to ensure we are not merely misled by a conditioned dogma.

Hypothetical deduction can provide us with this very test. Principle II requires us to deduce from any culture's basic socialstructural fact that: whatever contradicts the necessity or value of the principle defining this fact, will be ruled out from reproduction in this culture's mass media. All that is required to disprove the claim of Principle II, then, are assertions of fact, opinion or value reproduced in the mass media of a society which do in fact contradict the necessity or value of its system of social rule. Principle II, for example, would be falsified if reasoned arguments against unearned income or the control of the economy by private capital were reproduced in the Western mass media.

On the other hand, what is required to confirm the claim of Principle II is a consistent record of such facts, values or opinions being never or almost never reproduced in the mass media, however adequately they may qualify for such public presentation by the normal criteria of interest-value, transparency and factural warrant.

We may formalize the conditions for confirmation or disconfirmation of Principle II as follows:

(1) A set of qualifying arguments, positions or facts, a...n, contradict the necessity or value of the B.S.S.F. of a society, $S$.

(2) Arguments, positions or facts, a...n, are reproduced in some or all of the mass-media of society, $S$.

Conclusion: Principle $I I$ is disconfirmed.

\section{or}

(3) Arguments, positions or facts, a...n, are never or almost never reproduced in any of the mass media of society, $S$.

\section{Conclusion: Principle II is confirmed.}

Let us now consider a set of examples to stand in for arguments, positions or facts, a...n. If any or all satisfy condition (2), Principle II is rejected. If any or all satisfy condition (3), Principle II is accepted, until disconfirming evidence is produced. An extensive set of examples is now provided to ensure rigorous test of the Principle.

\section{Thirty Examples of the Unspeakable in the Mass Media of the English-Speaking World}

1. Taking more out than you put in as a regular practise-as in money profits-is morally wrong. 
2. The capitalist workplace is anti-democratic.

3. General Motors, Dupont, IT\&T, Standard Oil and Ford Corporations all produced military supplies for the Nazi armed forces during World War II while the United States was at war with Germany.

4. Unearned wealth should be abolished as a matter of just public policy.

5. The government needs to regulate the investment of Canadian/U.S. capital abroad to societies with poor human rights and environmental standards, so as to protect these standards in both North America and the developing world.

6. The free market means that those without money to buy what they need do not have the right to live.

7. The major player in the international drug trade since the Second World War, using drug enforcement laws to maintain its monopoly, has been the United States government to finance internationally illegal foreign interventions.

8. Over $70 \%$ of eligible U.S. and British voters did not vote for Reagan or Thatcher "landslides".

9. The arms race and international wars are very profitable for most multinational corporations.

10. The long-term pattern of U.S. and Canadian foreign policy in the non-white world has been alliances with fascist-type governments rather than their opponents.

11. The "free world" is not truly free because its citizens do not have the effective right to criticize the capitalist system.

12. The history of Western civilization is largely a history of genocide against nonwhite peoples and cultures.

13. The greatest danger to Canada's freedom and security comes from the United States.

14. There is no correlation between people's wealth and their merit.

15. In many cases, social ownership of major industries is sound social policy.

16. The very rich ought not to be admired, but rather condemned for their acquisitive self-interest at others' expense.

17. A small minority's monopoly ownership of society's means of production is an issue that needs to be carefully examined.

18. Pollution/poverty are specially advantageous to the major shareholders of private enterprise.

19. Our major social problems are caused by the profit imperative overriding all other values.

20. The belief that God sanctions our social order or our state at war is a superstition.

21 . There may be better alternatives for long-term sexual union than the private property structure of state-regulated marriage.

22. The Soviet Union pays significantly more than the world-price for imports from the countries of East Europe, and charges significantly less for its exports.

23. Socialist revolution has been by and large beneficial for the living standards of most citizens in societies where it has occurred.

24. Over $90 \%$ of Canadian citizens are not capitalists but members of the working class who depend for their living on wages or salaries.

25. Unions have historically led the struggle for improvements in health care, working conditions and social security for the population as a whole.

26. The business community has excessive political and economic power in our society.

27 . Our schools do not train the young to think critically, but to obey corporate or office authority without question.

28. The President and his leading advisors are provable war criminals.

29. Christianity calls for the redistribution of wealth.

30. The mass media are essentially a joint-stock company of profit and advertising for major private corporations. ${ }^{6}$ 


\section{Discussion}

These lines of reasoning all directly or indirectly contradict the value or necessity of our society's basic social-structural fact. According to Principle II, then, all will be ruled out from public reproduction. Note that it is not a question of this a priori exclusion being rationally warranted. Good evidence or reason can be given to support all of these assertions, and none commits an evident error of logic or fact. What is so interesting here is that the exclusion of such positions from public discourse does not depend at all on criteria of truth or falsity. They are unspeakable not because they are unreasonable, but because they in one way or other contradict justification of the structure of social rule by which they are surrounded.

That these statements might all be perfectly true, will not, therefore, save them from social excommunication; nor that they are perfectly true and of great social consequence as well. Indeed, one might say that the more warranted and momentous the meanings they bear are, the more totally unspeakable they become. (This point will be taken up under Principle III.)

The crux of the issue here is that independent of their claim to truth, and by means other than is detectable by recognized principles of logic, entire realms of discourse are without rational or empirical ground disqualified from candidacy for public assertion.

A very great deal of what might be reasoned, agreed with or said is involved here. Most of these unspeakables are in some way generic, and admit of countless particular variations on them. For example, a particular variation on number (1) would be that "It is unfair that Canadian corporations increased their profits in 1987 by 20 times more than wage-earners increased their wages"; or, more specifically still, "Bell Canada should not be allowed to penalize its employees for its previous year of the highest profits and revenues in
Canada, with a contract that provides for the elimination of thousands of union jobs". ${ }^{7}$ Both this generic statement and the innumerable possible particular variations of it will be blocked from social reproduction, however true or well reasoned they may be. This is the consequence of the illicit a priori identified by Principle II, and applies as well to all of the examples given above. Nonetheless, these positions are still not exhaustive of the kinds of assertion that are ruled out from public statement by the operation of this principle of unreason. Apart from the comparable sets of such positions which are unspeakable in the public domains of other kinds of social regime (e.g., anti-Party statements in statesocialist societies, skepticism of Allah's rule in Islamic societies), there are many kinds of position within our own social communication systems which are so proscribed, but not identified by our list or its variations: for example, "The solution to wife or child abuse is to restructure the family", or "Some illegal substances can be good for your development", or "Israel does not recognize the right of Palestine to exist". The possibilities here can be generated by the critical imagination without any limit but what is and is not compatible with the B.S.S.F. We are dealing, in other words, with whole worlds of meaning and position which are precluded from communication, not only without rational ground, but without the logical space of public medium to identify this rule of their exclusion.

There is not only a first-order rule against their social assertion, but a secondorder rule against recognizing there is a rule against their social assertion.

None of these positions or their variations, however, can be emancipated in the normal philosophical way by identifying some mistaken argument against them. Nor is any method of detection and correction given by contemporary philosophical theories such as those of Jurgen Habermas or Richard Rorty which appeal to norms of rationality inherent in discourse or conver- 
sation. Rather, what is involved is a much deeper obstruction to the process of reasoning; whether any will be permitted public statement prior to any argument arising. ${ }^{8}$ That these unspeakables may together appear as systematically slanted as the range of discourse from which they are excluded, is only a complementary indicator of the problem we are examining.

If we detach from our location within a contemporary social order and view the problem from afar, we can see the same transpropositional structure of fallacy at work in the past. In classical Greek culture, for example, the field of discourse at the very highest levels of reasoning was deformed by the same hidden a priori of unreason. It excluded as unspeakable, that is, lines of thought and reasoning which we would now regard as eminently reasonable: for example, assertions and arguments against human slavery, and evidence that would support this or any other analogously critical position. The same sort of deepstructured distortion of the field of reasoning occurs in feudal societies: for example, exclusion of any evidence, claims or arguments in criticism of feudal bondage, the existence or goodness of God, the absolutist rights of rulers, and so on. ${ }^{9}$ Any argument or step of argument that would in any way contradict the acceptance of these basic forms of social life was simply and with no rational warrant ruled out of candidacy in the public realm. Because such infrastructural proscription then, as now, blocks and misleads the reasoning process at the most fundamental levels, it is correspondingly deserving of logical excavation and targeting. It undermines the reasoning enterprise at its foundations.

\section{First Conclusion}

Insofar as proper reasoning entails (1) openness to evidence and issues for argument without external constraint on what evidence and issues for argument are rais- ed and (2) examination of presuppositions and conclusions rather than mere adherence to them without rational warrant, the structure of determination identified by Principles I and II violates the nature of proper reasoning.

The derangement of reason implied by this structure of determination is not a fault of any one step or route of reasoning, as we have seen. No error of premise, of inference, of conclusion of any argument or case is required for this disorder to be in place. It waylays reason on a deeper level, at the level of an underlying structure of particular arguments and cases taken together which may all in themselves be valid and sound, but nonetheless misdirected and misleading in virtue of this structure determining them. In other words, the fallacy here is a defect in the form of a field of reasoning, not of any argument or argument step within it.

This field of reasoning may include an infinitude of particular arguments or argument steps which are, distributively analysed, without fallacy. Yet notwithstanding such possibility of atomic soundness, the discourse affected by this underlying structure of determination is radically deformed, and more and more misleadingly so as it operates underneath the reach of detection. It is a deep-structural fallacy set into the frame of discourse itself and constitutes thereby the most systemically distorting bonds of illusion against which critical thinking has to contend.

\section{Principle III}

We now propose a third principle which extends our understanding of this covert structure of the communications field fallacy.

Exclusion of a statement or set of statements from the range of what can be said in the public realm occurs in proportion to its contradiction to acceptance of the basic social-structural fact as necessary and good. 
This principle allows for variation and complexity in what can and cannot be said in public discourse. It covers those myriad possibilities of nuance, emphasis, co-optive reformulation, selective deletion, marginal occurrence and so on which so abound in natural language phenomena. We can in accordance with this principle make further distinctions within what is pre-empted from the permissible range, and thus more exactly understand the margins of both what is excluded and included in the scope of the speakable.

These distinctions are open to alternative or elaboration. Proposed here is a simplified, graduated categorization:

1) ruled out as a priori unspeakable eg. (1), (2), (4), (5), (6), (11), (12), (16), (18), (19), (20), (26), (28), (30) above.

2) omitted eg. (5), (6), (8), (9), (13), (17), (24).

3) selected out eg. (3), (10), (15), (22), (23), (25).

4) marginalized eg. (7), (14), (20), (21), (27), (29).

Defining principles of these proposed distinctions can be elucidated beyond what is afforded by the ad hoc examples given in illustration.

Discourse is ruled out as a priori unspeakable: insofar as it is in principle inconsistent to accept both its content and the necessity and value of the B.S.S.F.

It is omitted: insofar as its content exposes a discreditable property of the B.S.S.F., but is not in principle incompatible with the acceptance of the value and necessity of the B.S.S.F.

It is selected out: insofar as its substantial or frequent re-iteration in the media would challenge acceptance of the B.S.S.F., but not its passing appearance.

It is marginalized: insofar as its appearance at the margin of public discourse does not contradict, but justifies the B.S.S.F. as tolerant of critical positions.

The same type of position or argument could, through time, move from being ruled out as a priori unspeakable to being merely omitted or marginalized, in accordance with how it is modified to accord with the B.S.S.F. or, conversely, how the B.S.S.F. is modified to accommodate it. Pope John Paul II's declaration of "the priority of labour over profits" in his 1981 encyclical Laborem Exercens, for example, modifies a formerly unspeakable position in the media to an omitted one. On the other hand, the espousal of women's right to choose abortion moves from being straightforwardly unspeakable 25 years ago to marginalized and struggling inwards as the B.S.S.F. itself modifies towards increasing participation by women in it as independent agents. These are explanation sketches of the lines of analysis that can be followed in understanding the variety-admitting relationship between determining basic social-structural facts and public argument possibilities. Because this relationship is, however, always contra-rational for the reasons elucidated on page 140 , such variation in what can and cannot be supposed, inferred and argued does not mitigate the hold of this underlying structure of unreason, but only masks it in the play of diversity. This play of diversity is essential to the appearance of "pluralism" in a society when its communication field is in fact systematically intolerant of basic alternatives or criticisms.

\section{The Speakable: Operations within the Range of Public Discourse}

Just as there are operations to exclude from the range of what can be said in the public media, so there are complementary operations of selection and exclusion within this range. Again, the existential ground of these operations is the basic social-structural fact as defined under Principle $I$, and the form of its determination is as defined by Principles II and III.

But Principles I, II and III do not yet tell us what will be selected for production in the public realm among the countless viable possibilities that do not contradict 
acceptance of the B.S.S.F. We require a principle of selection within this permissible range to complete our general framework of analysis.

It can be defined as follows:

\section{Principle IV}

What validates the basic social-structural fact as necessary or moral, and invalidates opposition to it as impractical or immoral, qualifies for selection for mass media production.

Here again, such a principle of selection violates the nature of reasoning by the closure to evidence and issues it entails, and by the unwarranted acceptance of deep presuppositions it systematically reinforces. But it differs from the disorder identified by Principles II and III in bearing a positive bias of selection rather than a negative bias of exclusion. It is not so destructive of reason's proper course as is the derangement described by Principles II and III which block and silence entire domains of inquiry - but operates rather to select for reproduction what is most favourable to acceptance of the B.S.S.F. in what is left over for assertion and argument.

That is, within the range of what can be publicly said, there is a bias towards what validates the B.S.S.F. and/or invalidates opposition to the B.S.S.F. which rules against the middle ground of what does neither. Principle IV identifies this systematic slant. For example, the publicly speakable might be quite neutral in content without either contradicting or promoting the B.S.S.F., or detached from all such concerns, or in some other way permissibly non-contradictory in its bearing. But in fact, it is proposed by Principle IV, what is stated and reproduced within the range of the publicly speakable tends to be either a direct or indirect justification of the necessity or value of the B.S.S.F., or a direct or indirect condemnation of what opposes this B.S.S.F.

As with the operations of determination identified above, there are countless possibilitics of illustration here, and there are different sorts of classification into type by means of which we can organize these instantiations of Principle IV into subset classification.

Let us consider the schema of distinction in terms of the following order:

(1) selection of assumptions,

(2) selection of events and issues and

(3) selection of descriptive predicates.

At all three levels of selection, the principle for selection is: to favour what validates the existing B.S.S.F. as necessary/good, and what invalidates opposition to the existing B.S.S.F. as impractical/bad.

\section{Selected Assumptions}

Reasoning and assertion are normally conducted on an unstated basis of implicit assumptions. These assumptions are typically not raised as a step of the argument insofar as they are already acceptable to the audience in question. They are simply presupposed. What Principle IV states is that there is a structural bias in public discourse towards such assumptions which conform to this principle, and not other, more rationally acceptable assumptions which do not.

For example, in discussing or reporting an earthquake in Guatemala, a published account in the North American media would repose on a great variety of contextually acceptable assumptions - about cause and effect, geographical plate shifting, photographic fidelity, the organic structure and needs of humans, the intersubjective efficacy of language, and so on. But if it comes to a choice, implicit or explicit, between acceptable assumptions, none of which contradicts acceptance of the B.S.S.F., the ones which will be favoured will be those that comply with Principle IV and not others equally or more plausible. 
To pursue the example, there may be conflict between army and peasant guerrilla forces at the site of this Guatemala earthquake, and the acceptable background assumptions to account for this complication could be that the guerrillas are moved by regional impoverishment and the need to replace an idiocyncratically brutal military dictatorship repressing them, or that they are moved by external communist intervention and a Marxist-Leninist design to overthrow capitalism. Further background assumptions might be that U.S. assistance is just normal ideological grandstanding or the expression of a basically generous American social order. Principle IV holds that in both cases the latter kind of background assumptions and not the former will be favoured for selection within the range of what does not contradict the B.S.S.F.

More basically still, the peasant uprising could be understood from the background assumption that once fundamental human needs reach a certain threshhold of deprivation, people revolt; or it could be understood from the background assumption that overlooks human needs in favour of moralizing qualms about those who revolt. Principle IV holds again that it is the latter background assumption that will be selected as the public standpoint from which to ascribe and reason, and not the former: because the latter tends by analogue to both justify the B.S.S.F. and condemn opposition to it, whereas the former leaves such matters open to further judgement and inference.

\section{Selection of Events and Issues}

As with background assumptions, so with events and issues themselves, what is selected for public reproduction is selected from a great range of possibility. There are a limitless number of events and issues at any given time which qualify for public speakability by not contradicting acceptance of the B.S.S.F. within whose determining confines they arise. Here too, however, Principle IV states that from among these countless possibilities, those will be favoured that justify conformity and/or condemn non-conformity to this B.S.S.F.: for example, the exploits and contributions of B.S.S.F. leaderships and beneficiaries, and the wrongs and defects of B.S.S.F. victims and opponents. ${ }^{10}$ Principle IV holds, that is, that these kinds of events and issues will be normally selected for public presentation and discussion rather than those within the permissible range which would provide a balanced "mix", or events and issues which have no such political implications or bearings.

It might be objected that the mass media in fact prominently report and discuss events and issues of the latter, "neutral" sort: human disasters, accidents, happenings, problems and so on with no political import to them. Such a view misses the underlying structure of selection whose operation precisely depoliticizes these sites of debate in accordance with Principle IV.

Consider, for example, the Guatemala earthquake referred to above, which can be seen as a paradigmatic occurrence in the developing world from neighbouring El Salvador to the Philippines. It is incontrovertibly the case that such earthquakes cause the human deaths they do because the dwelling-constructions within which those killed live, and not those much wealthier, are too fragile from the poverty of their inhabitants to withstand these earth-structure shifts. To select against report and discussion of this fact conforms to Principle IV: both because it excludes from attention a fact that might constitute grounds for criticism of the B.S.S.F. of that society and, by analogue, of the larger economic order of which it is a part; and because, thus "neutralized" of such political content, the earthquake disaster can become an occasion for affirmation of the B.S.S.F. by highly publicized steps of 
official relief extended to its victims. In this way, what appears to be an exception to the operation of Principle IV turns out, on closer examination, to be in confirmation of it.

Again, very much could be said here in further illustration and development of Principle IV's operation. We will restrict ourselves to three typical patterns that manifest it. First of all, less consequential harms, for example, of embryos by abortion, are selected for media debate rather than much more consequential related harms, for example, the massive starvation and deprivation of children.

Secondly, the issue of individual personalities in social and political movements or, on the other side, social and political problems, is selected for public exposure rather than these movements and problems themselves: for example, leader "images", or idiocyncrasies rather than policy positions or statements, and Watergate or Contragate exposés of individuals rather than of underlying systemic crimes these individuals manifest.

Thirdly and perhaps most significantly in prescribing the agenda of debate in conformity to Principle IV, advocacy of relatively right or extreme-right positions on the political spectrum is selected for repeated report and description, whereas advocacy of relatively left or extreme-left positions is seldom reported or described (eg. cold warriors, neoconservatives, evangelical bigots, anti-Semites, racists and so on rather than radical disarmament advocates, democratic and religious socialists, Marxists, third-world revolutionaries and so on).

This weighting of the range may be the most importantly distortive operation of the entire system of fallacy we are examining because it continuously generates a spurious " middle ground" or "centre" upon which other operations depend for their consensual appeal. That is to say, the range of positions which is publicly visible shifts as a whole towards positions which are in- tolerant of what criticizes the society's established order. Report of attacks against such positions from "extremists" as well as "moderates"' is thus made to appear as "balanced", as even-handedly presenting "both sides of the story."

\section{Descriptive Predicates}

Principle IV also applies to the language in terms of which the agents and positions of those events and issues that are selected for public communication are, in turn, described. That is, according to Principle IV, validating predicates will be used in description of agents and positions that are pro-B.S.S.F. in disposition; and invalidating predicates will be used in description of agents and positions that are antiB.S.S.F. in disposition. For example, the same kind of government action, say, police crackdown on demonstrating workers or students, will be described as "tough", "no-nonsense", "firm" or the like, on the one hand, or "violent", "brutal", "repressive" or the like, on the other, depending on whether the action in question is by a state that is supportive of, or hostile to, the contextualizing B.S.S.F. Favourable and unfavourable predication, that is, will not be determined by a factual difference in the actual behaviour involved. It will be prejudicially determined in accordance with whether it confirms the B.S.S.F. as necessary and good, or discredits opposition to it as unworkable or wrong.

Just as with selective assumptions, events and issues, an immense variety of possibilities remains consistent with the operation of Principle IV. We will here identify only some standard examples. In each case, the first term of the predicate opposition has as its referent what is proB.S.S.F. in disposition, and the second term has as its referent what is anti-B.S.S.F. in disposition. In all cases, the individually acceptable use of these descriptive predicates 
varies in accordance with the systemic bias defined by Principle IV, and not in accordance with reason or factual warrant:

"freedom fighter" vs. "terrorist"

"stable" vs. "dictatorial"

"enthusiastic" vs. "well orchestrated"

"austere" vs. "draconian"

"ally" vs. "satellite"

"patriot" vs. "fanatic"

"offer" vs. "demand"

"commentary" vs. "propaganda"

"leader" vs. "boss"

"courageous" vs. "extremist"

"protecting national interests"

vs. "expansionist"

"realistic" vs. "unscrupulous"

\section{Conclusion}

The structure of the communications field fallacy consists in four underlying principles of determination, each with its own differentiated operations. The reason that this system of distortion has remained unmarked by logical analysis is that its disorder is not detectable in any argument or argument step, but only in the pattern of these across an overall field of public discourse.

Since this system most consistently misleads thought and reason in the realm of mass communications, this realm has been the general focus of our analysis here. But because the frame of reference constantly reproduced in the public media is, over time and without critical alternative, appropriated by people as their own, if only by osmosis and repetition, we need to consider this structure of deception as reaching beyond the media into other realms of communication as well-as an acculturated frame of reference borne by individuals themselves at all levels of communication, including the academic. It confronts us with a possibly universal system of dupery by which reason and thought are misled with no clear boundary of cultural location.
Although our examples have specifically illustrated this system's operations in Englishspeaking society's mass communications print network, it would be quite mistaken to restrict its determination to this domain or this civilization.

To go one step further, we need not limit the operation of this deep structure of deception to even the realm of verbal assertion and reasoning as a whole. Signs and expressions of all sorts may also be so determined in what is excluded and what is selected for communication. The frequency or absence of pictures reproduced across a culture, for example, and their role in validating or invalidating their referents, admit of analysis in terms of the same principles we have identified above. We may be confronting here, in other words, the basic structure of a general grammar of deception whose determination of what is and is not socially reproduced operates across sign and communication systems. ${ }^{11}$

If the system has then no boundaries to its determination, yet its recognition is ruled out by its very operations, are we condemned to an iron cage of signification with no hope for emancipation from its hold? It is here that the foundations of reason and the academy that sustains them may have become sufficiently autonomous within our culture to allow the detection of our bars.

Once recognized, these bars are not easily maintained. The gates to the movement of ideas are obliged to open in proportion to public recognition of their obstruction, lest the claim of "freedom of the press" lose its public credibility. The contradiction between what is said to be and what is, between basic social value and socialstructural impediment, between the nature of thought and what constrains it, this multiple contradiction at the very axes of our shared being is a dialectic that dissolves the forms of its containment the more they are understood. The first and major step in the release of public consciousness from the distorting bounds of its control is to recognize that they exist. 


\section{Summary Figure}

\section{BASIC SOCIAL STRUCTURAL FACT} (B.S.S.F.)

Principle I: Large capitalist corporations or a state party control production and distribution of social goods so as to maximize capital/social command owned by corporations/party

determines

Range of Possibility of What Can Be Said in the Mass Media

Principle II: Nothing appears in a society's mass media which contradicts the necessity or value of B.S.S.F.

\section{OPERATIONS OF EXCLUSION FROM THE RANGE}

Principle III: Degree of Exclusion is in proportion to contradiction of B.S.S.F.

Operations: 1. Ruled out as a priori unspeakable

2. Omitted

3. Selected Out

4. Marginalized

\section{OPERATIONS OF SELECTION WITHIN THE RANGE}

Principle IV: Select what validates B.S.S.F. as necessary/moral and what invalidates opposition to B.S.S.F. as impractical/ immoral

Operations: 1 . Selection of presuppositions

2. Selection of events/issues

3. Selection of descriptive predicates

\section{ACTUAL PUBLIC DISCOURSE}

Implicit and explicit propositions, arguments and signals ranging from optimally functional justifications of B.S.S.F. to verbal or non-verbal expressions that never overtly challenge B.S.S.F.

\section{Notes}

*This paper was originally prepared for presentation to the Association for Informal Logic and Critical Thinking, Canadian Philosophical Association Annual Meeting, Windsor, May, 1988. I am especially indebted to the Editors of Informal Logic, Anthony Blair and Ralph Johnson, for their support and suggestions, to David Hitchcock for his valuable bibliographical assistance, to Howard Kahane for the reference to Mark Twain, to G.A. Cohen for his criticisms, and to Noam Chomsky, Jim Christoff, Homer Hogan, Alex Michalos, Bertell Ollman, Howard Woodhouse and Barrie Zwicker for their very supportive interest during various stages of this paper's construction.

1 Richard Paul has argued that ego- and ethno-centric worldviews can fix people to a dogmatic, undialectical perspective which may actually use logical techniques to buttress itself against critical reflection. (See Richard Paul, "Teaching Critical Thinking in the 'Strong' Sense: A Focus on Self-Deception, WorldViews and Dialectical Mode of Analysis. Informal Logic Newsletter, May 1982 (Vol. IV, No. 2) pp. 2-7 and 'Programmatic Approaches to the Teaching of Thinking Skills" in Teaching Thinking Skills: Theory and Practice, ed. Joan Boykoff Baron and Robert J. Sternberg (New York: W.H. Freeman and Co.) 1987, pp. 127-145. According to Paul and to Bertell Ollman in unpublished manuscript, "The Meaning of Dialectic", the problem here is insoluble by logical analysis, and can only be corrected by education in dialectical method.

2 That the mass media of the contemporary world are under the monopoly ownership control of a very small fraction of the world's population is indicated by the following figures. Four new agencies, Reuters, France Presse (AFB), Associated Press (A.P.) and United Press 
International (UPI) " provide $90 \%$ of the entire foreign news output of the world's newspapers and radio and television stations" (cited in Rowland Lorimer and Joan McNulty, Mass Communication in Canada (Toronto: McClelland and Stewart), 1987, p. 232). The authors also point out that two-thirds of the school text market in North America is controlled by eight multinationals (Ibid, p. 108). Twenty-seven corporations control most of the American mass-media, according to the recently revised edition of Ben Bagdikian's The Media Monopoly (New York: Beaverbrooks, 1987), a figure that has dropped by almost $50 \%$ from the 1983 first edition. "Ten business and financial corporations control the three major television and radio networks (NBC, CBS, ABC), 34 subsidiary television stations, 201 cable T.V. stations, 62 radio stations, 20 record companies, 59 magazines including Time and Newsweek, 58 newspapers including The New York Times, the Washington Post, the Wall Street Journal and the Los Angeles Times, 41 book publishers and Twentieth Century Fox" (Michael Parenti, Inventing Reality: The Politics of the Mass Media (New York): St. Martin's Press, 1986, p. 27). Parenti also points out that "a 1975 Senate intelligence committee found that the C.I.A. owned outright 'more than 200 wire services, newspapers, magazines and book publishing complexes' and subsidized many more", an ownership to which he proceeds to show 50 further media outlets and over 12 book publishing houses have since been discovered (Ibid, p. 233). According to Canada's Royal Commission on Newspapers (Minister of Supply and Services Canada, 1981), p. 1: "Three chains control nine-tenths of French-language daily newspaper circulation. Three other chains control two-thirds of Englishlanguage circulation... under concentrated [chain] ownership, three-quarters of the total. In seven provinces... twothirds or more of provincial circulation is controlled by a single chain'.

This overall system of monopoly is made internally consistent by the common interests of its chain owners and corporate sponsors, and by corresponding unstated editorial policy to keep news reports consistent with each other. In the words of Peter Raymont's documentary of the news production process at ABC National News headquarters in New York, The World is Watching (Toronto Investigative Productions, 1988): "Above all, reporters must match what their rivals file from the field. Any variation makes editors nervous. So although the news business is driven by competition, everyone's story looks and sounds the same."

3 Noam Chomsky has documented the details of the distortion of public discourse by its context of power more thoroughly than perhaps anyone in the twentieth century, especially in a series of volumes published almost entirely by a small Montreal press: (with Edward S. Herman) The Political Economy of Human Rights Volumes I and II (Montreal: Black Rose Books, 1979), Turning the Tide (Black Rose Books, 1986), On Power and Ideology, (Black Rose Books, 1987), Pirates and Emperors (Black Rose Books, 1987), and (with Edward S. Herman) Manufacturing Consent: The Political Economy of the Mass Media (New York: Pantheon, 1988). Chomsky's overwhelming empirical case, however, is confined to public discourse within the United States, and to the topic of U.S. and Israeli foreign policy. Because of these regional and topical restrictions of his inquiry, and because his analysis is of facts and statements in these specific contexts rather than of the system of rules or principles underlying public communications as a whole across cultural boundaries, his inquiry does not achieve that level of 
abstraction and universality sought by philosophy and logic. It does, however, provide encyclopaedic confirmation of this system as it is formally defined in this paper.

4 For thorough documentation of the U.S. Federal Bureau of Investigation's monitoring and often black-listing of most of the great American writers of the twentieth century for their suspected advocacy of "subversive" positions, see Herbert V. Mitgang, Dangerous Dossiers (New York: Donald I. Fine, 1988). The more extreme method of killing those who speak the unspeakable is also widespread. It not only includes the recent widely publicized case of the Ayatollah Khomenei's order of execution of writer Salmon Rushdie but the thousands of deaths reported annually by Amnesty International for no apparent offense but non-violent expression of a social or political opinion. In the extremity of means for enforcing the unspeakable may be the inverse measure of a culture's advancement towards humanity. But by whatever method the limits of public communication are held to conformity to Principle II, such limits are contrary to reason. This is worth emphasizing because we may be otherwise inclined to overlook these barriers to reason merely because their imposition is not by directly violent means.

5 Anthony Blair has suggested that the problem of exclusion here might be conceived as a violation of the requirement of sufficient evidence. The reason that the principle of sufficient evidence does not apply here, however, is that it means only that the evidence given for any conclusion is adequate to justify the inferences from it. (See, for example, Ralph Johnson and Anthony Blair, Logical SelfDefense (Toronto: McGraw-HillRyerson, 1983), pp. XVI, 34, 41-46, and 195). The fallacy of the unspeakable, on the other hand, is not a matter of evidence or premises being insufficient to justify the conclusions drawn from them, nor indeed a matter of any fallacy of a line of argument at all. It is a question of excluding positions from being presented or argued in the first place: a fallacious pattern of what is not said in an overall field of discourse, rather than an error in the relationship between premises and inferences of what is said.

6 These statements represent a mixture of assertions of fact, analysis and value. This is to show that the realm of the unspeakable embraces a full range of logical modes. Questions may arise as to the empirical warrant for numbers 3 and 7 in particular. The facts to support these claims, if not these claims themselves, are available in Charles Higham, Trading with the Enemy (New York: Dell, 1983), Alfred McCoy, The Policies of Heroin in South-East Asia (New York: Harper and Row, 1972), and Jonathan Kwitny, The Crimes of Patriots (New York: Simon and Shuster, 1987). Interestingly, the very newsworthy content of this evidence remained unspeakable in the major newsprint, magazine, radio and television media during the 1988 U.S. Presidential elections, though one might have expected the politics of democratic opposition to bring to light facts whose disclosure would strongly favour the losing candidate. In such cases, we can see how the lines of the unspeakable run beneath the lines of political parties and electoral contest itself.

The unspeakability of position 28 , a similarly controversial claim of fact, was recently confirmed by the media's blackout of the International War Crimes and Crimes Against Humanity Tribunal held in Toronto prior to the World Economic Summit in July 1988. At the Tribunal, over 50 witnesses gave eyewitness and expert testimony under oath and through examination by legal counsel to the perpetration of these 
crimes as these are defined by international law and the Criminal Code of Canada, much of the evidence implicating President Ronald Reagan of the United States and Prime Minister Margaret Thatcher of Great Britain of war crimes and crimes against humanity. These crimes, as defined by the Criminal Code of Canada, (Section 6, 1.96) include "murder, extermination, enslavement, deportation, persecution or any other inhumane act that is committed against any civilian population." Although the witnesses included former cabinet-level government officials, two high-ranking ex C.I.A. agents, internationally recognized legal scholars and scientists, many direct victims of torture and family-member assassinations, trade unionists and civil rights activists from 4 continents as well as missionary clergy of the major Christian churches, no report of the evidence indicating war crimes was published by any of the invited major newspaper, magazine, television or radio stations.

7 The precise figures for average profit and average wage rises during 1987 are $52.2 \%$ for the top 1000 Canadian corporations, and $2.7 \%$ for Canadian wageearners. (Report on Business Magazine, July 1988, pp. 90-1). The Bell Canada profit and revenue rankings are provided in the same annual report.

8 In his paper presented to the Association for Informal Logic Critical Thinking, Windsor, 1988, entitled "On Defining Critical Thinking: A Pragmatic Contribution", Ralph H. Johnson proposes that the "acid test of whether someone is a critical thinker is how the individual conducts himself when challenged". He further suggests that failure of this test is indicated by one who "refuse(s) to admit the possibility of a challenge", "simply ignore(s) the challenge", or "cling(s) tenaciously to the belief' (pp. 9-10). Johnson's indicators point out just how serious the blockage to critical thinking is in the media of public communication, where the challenge is, by the operations of exclusion defined, not permitted to arise in the first place. In accord with established thinking on the subject, however, Johnson's indicators are applied only to particular bearers of reason's obstruction, not the much more pervasive disorder of such obstruction in a social system of communication itself.

Jurgen Habermas in his monumental study, The Theory of Communicative Action, Volume II, trans. Thomas McCarthy (Boston: Beacon Press, 1987), p. 346 does acknowledge the depth of this structural deformation of discourse, but only en passant: "The political system produces mass loyalty in both a positive and a selective manner: positively through the prospect of making good on social-welfare measures, selectively through excluding themes and contributions from public discussion. This can be accomplished through a sociostructural filtering of access to the political public sphere, through a bureaucratic deformation of the structures of public communication, or through manipulative control of the flow of communication." Habermas does not pursue this line of analysis in the remainder of his 900 -page study.

9 These epochal blocks to philosophical debate are explored in my "Philosophical Method and the Rise of Social Philosophy" Eidos, December 1981 (Vol. II, No. II), pp. 139-76. Their continuing determination of curricula in the present educational system is analysed in "The History of Inquiry and Social Reproduction: Educating for Critical Thought', Interchange, Volume 19, Number 1, 1988, pp. 31-46.

${ }^{10}$ For the way in which perceived opponents of the B.S.S.F. are continuously diverted to for irrelevant attack in fallacious moves within the permissible 
range of discourse, see my "Argumentum Ad Adversarium', Informal Logic Winter 1986 (Vol. VIII, No. 1), pp. 27-36.

${ }^{11}$ Because pictures are typically the most prominent vehicles of communication in contemporary culture, it may well be that their selection and exclusion is more important in the mass media than what is conveyed by natural language itself. This centrality of the visual in message transference is generally overlooked by informal logic and contemporary philosophies of communication. The structure of fallacy identified in this analysis, however, applies to the pictorial as well as the verbal in the communications field. Indeed its application here may be more revealing. Determination of what is and is not reproduced as visual representation in a culture has been less subject to critical scrutiny than what is reproduced as print. Journalists, for example, normally have no say in or knowledge of what pictures (or headlines) will accompany their copy. This is decided externally and the products of these decisions are generally not analysed for patterns of misrepresentation. Yet as the saying goes, "Who controls the pictures controls the show." Consider, for example, the comparative frequency, size, placement and favorability of pictures which are reproduced over time in the major North American and British media of candidates from the right and from the left of the political spectrum. Though our analysis here has attended to the standard conceptual object in laying bare the structure of the communications field fallacy, this structure of deception more covertly determines the visual contents of the media as well.

Dr. John McMurtry, Department of Philosophy, University of Guelph, Guelph, Ontario, Canada N1G 2W1 